\title{
OUTCOME OF LATE PRETERM NEWBORNS
}

Manal ELhawary $^{(1)}$, ELkassem Elgameel ${ }^{(2)}$, Sayed Amin $^{(3)}$, MarwaMaddboly $^{(4)}$.

(1) Professor of pediatrics, Faculty of medicine, FayoumUniversity,Fayoum, Egypt.

(2) Assistant professor of pediatricsFaculty of medicine, FayoumUniversity,Fayoum, Egypt.

(3) Assistant professor of pediatricsFaculty of medicine, FayoumUniversity,Fayoum, Egypt.

(4) Medical student,M.B.B.Ch,benisuef University, Egypt

\section{Corresponding author: Marwa Abd Almonem Maddboly}

Fax: +2 084636583

Tel : 01094262677

\section{ABSTRACT}

Background: Preterm birth rates continue to rise. Suggestions have been made that preterm birth rates have also increased because of a dramatic rise in late preterm births, defined as births between 34 weeks and 36-6/7 weeks of gestation. Latepreterm births are considered functionally mature but, several line of evidences suggest that, compared with term neonates, they have a higher risk of complications.

Objectives: The present study was done to compare the outcome of late preterm infants born in our hospital, compared to those born at term.

\section{Patients and Methods: This is a} prospective study conducted on 250 newborn born in maternal unit and neonatal intensive care unit of Fayoum University Hospital and BeniSuef General Hospital during 6 consecutive months(the period from May 2015 to November 2015). The study sample comprised late-preterm infants (cases) and a group of full term newborns(controls). Maternal, gestational and neonatal variables were analyzed. Means and standard deviations were used to compare numerical variables between case and control groups using KolmogorovSmirnov test (KS) and the Mann-Whitney test.
Results: The study sample comprised 180 (72\%) were full term and $70(28 \%)$ were late pre term. 111 were males and 139 females. Mothers aged below 17 and over35 years and/or with a history of previous premature deliveries had a higher proportion of late-preterm children. More than half of the late preterm newborns $(52.9 \%)$ were admitted to NICU where as $26.7 \%$ of FT newborns needed admission. LPT delivery was associated with an increased risk of neonatal morbidity, including jaundice requiring phototherapy (34.3\%vs. $7.8 \%$ ), respiratory morbidities (32.9\%vs.13.9\%), hypoglycemia $(8.6 \%$ vs. $1.7 \%)$.

Conclusion and Recommendation: Latepreterm newborn infants exposed to a greater risk of intercurrent conditions during the neonatal period. The best treatment of late prematurity is to prevent it. Public and professional awareness of the problems associated with late prematurity should be highlighted. Follow-up programs for early detection and intervention for long term complication are recommended.

KEYWORDS: neonatal morbidity, late premature infants, neonatal intensive care units. 


\section{INTRODUCTION:}

Preterm birth, defined as birth that occurs on or before the end of the 37th week (259th day) of pregnancy, counting from the first day of the last menstrual period, is a conventional medical terminology endorsed by the American Academy of Pediatrics (AAP), the American College of Obstetricians and Gynecologists (ACOG), and the World Health Organization.[1,2] Although preterm infants is a category known for its high mortality and various morbidities, the overall incidence of prematurity-related complications decreases significantly if the infant was born after 34 weeks' gestational age. In obstetric and pediatric practice, those infants born with less degree of prematurity are often considered functionally as full-term, and often are cared for in the well-baby nursery after birth. It was not until the last decade that special health concerns of these "nearterm" infants arose.[3,4 ]Mounting reports identified increased morbidities that differentiate late preterm and term infants. Furthermore, there was an awakening concern about using the term "near-term," which connotes that the infant is almost term and almost fully mature, might lead health care professionals to underestimate the inherent risks to these infants.

General consensus came with the 2005 workshop, "Opti $\neg$ mizing Care and

\section{METHODS}

This was a prospective cohort study of 70 late preterm live births (340/7 to $366 / 7$ weeks of gestation) served as a case and 180full-term infants (370/7 to 406/7 weeks of gestation) as a control born in maternity unit and admitted in neonatal intensive care unit of Fayoum University Hospital and BeniSuef General Hospital during 6 consecutive months (the period from May 2015 to November 2015), their maternal obstetrical factors and neonatal demographic distributions were collected. Maternal obstetrical factors included hypertensive disorder of pregnancy,
Outcome of the Near-Term Pregnancy and the Near-Term Newborn Infant," sponsored by the National Institutes of Health, which recommended that infants born at 340/7 through 366/7 weeks' gestation after the onset of the mother's last menstrual period be referred to as late preterm to emphasize that these infants are preterm and, as such, are at risk of immaturity-related medical complications. [5] In past decades, rising trend of preterm births was caused by an increase in the birth rate of late preterm infants. [6] In those infants born late preterm, increased morbidities related to physiologic immaturity of the respiratory, metabolic, neuro $\neg$ logic and immunologic systems have been observed.[7] It was also noted that they had a higher rate of hospital readmission during the neonatal period. $[8,9]$

It is important to discern the epidemiology and the actual neonatal morbidities of late preterm delivery, so that evidence can be provided to guide obstetrical decisionmaking and to direct anticipatory care for infants at risk. The aim of our study was to examine the prevalence and clinical complications that could be associated with late preterm birth, as compared to term.

diabetes, mode of delivery (cesarean section or vaginal delivery), indication for delivery (onset of labor, rupture of amniotic membrane, ante partum hemorrhage, abruption placenta, or fetal distress) and indication for cesarean section (previous cesarean section, placenta previa, breech presentation).

Demographic features of the newborn included gesta $\neg$ tional age (calculated from onset of the mother's last menstrual period), sex, birth weight (in grams obtained after delivery within 1 hour after birth), and 
APGAR scores at 1 and 5 minutes after birth.

Outcome measures of neonatal complications included neonatal morbidities, admission to the neonatal intensive care unit (NICU; including special care nursery), duration of hospital stay if admitted to NICU or, rate of hospital readmission within the neonatal period, and neonatal death. Criteria of NICU, respiratory or circulatory instability, hypoglycemia, signifi $\neg$ cant hyperbilirubinemia, suspected sepsis, or the need for close monitoring as assessed by a neonatologist.

Neonatal morbidities included respiratory complications [respiratory distress syndrome (RDS), transient tachypnea of newborn (TTN), persistent pulmonary hypertension (PPHN)and pneumonia], apnea events (cessation of breathing for longer than 20 seconds, or any duration if accompanied by cyanosis and bradycardia), neurologic complications (convulsion, periventricular leukomalacia, intra ventricular or intracranial hemorrhage), hypoglycemia (blood glucose level of less than $40 \mathrm{mg} / \mathrm{dL}$ in capillary or venous blood sample, temperature instability (core body temperature of less than $36.0^{\circ} \mathrm{C}$ or higher than $38.0^{\circ} \mathrm{C}$, detected within 4 hours after birth and every 8 hours until discharge), hyperbilirubinemia needing phototherapy (indication for phototherapy based on

\section{RESULTS}

A total of 250 infants were recruited for the study, 70 LPTI in the case group and 180 FTI in the control group. There were no differences between the two groups in terms of mean maternal age; $27.3 \pm 6.9$ years in the LPTI group vs. $26.3 \pm 6.7$ years in the FTI group ( $\mathrm{p}=0.055)$.

Notwithstanding, mothers below 17 and over 35 years old were associated with a higher rate of LPTI $(p=0.001)$.

There was no difference in mothers' educational level either and in both groups the largest subset comprised mothers who guidelines from AAP 20109),

hypocalcemia, and feeding difficulty.

Investigations that were done complete blood count (CBC) with differential to all cases and reticulocytes count when needed, c-reactive protein (CRP) to all cases and blood culture when needed, serum $\mathrm{Ca}$ (total / ionized) and electrolytes when needed. Total and direct billirubin in cases of jaundice and for hemolytic jaundice (ABO and $\mathrm{RH}$ ) were done, random blood glucose (RBS), ABG when needed, Chest X-Ray when needed, echocardiography when needed, CT brain when needed.

Statistical analysis was performed using SPSS software version 18.0 (SPSS Inc, USA by IBM, version 18.0). Data analysis was performed with the Pearson chi-square test for categorical variables. Continuous variables were analyzed using the independent t-test for between-group comparison. Differ-ences were considered statistically significant when $\mathrm{p}<0.05$. Adjusted $\mathrm{P}$ values for multiple post-hoc comparisons after classification of the individuals of different gestational ages into 4 groups were calculated by using the Bonferroni correction method to account for the problem of multiple testing. $P$ value of 0.05 was divided by number of comparisons i.e. $3(0.05 / 3)$. Thus, test results with $\mathrm{P}$ values $\leq 0.017$ were considered statistically significantly different.

had not completed primary education, at $39.7 \%$ of the mothers of LPTI and $32.9 \%$ of the mothers of FTI.

With regard to obstetric history, the LPTI mothers had had $2.1 \pm 0.9$ previous pregnancies and the FTI mothers had had $2.00 \pm 0.9$ previous pregnancies. There was no statistical difference between the groups in terms of history of miscarriages (17.2 vs. $15.0 \%)$ or still births (1.3 vs. $1.4 \%)$.

However, the mothers of LPTI had had twice as many previous premature 
deliveries (14.3 vs. $6.1 \%)$ than the mothers of FTI $(\mathrm{p}=0.036)$.

Table 1 shows the results of the comparison of the groups in terms of variables relating to pregnancy and delivery.

Premature birth was associated with hypertension, PROM and maternal infections.

There was a predominance of cesarean deliveries in the LPTI group and umbilical cord pathologies were more common in the FTI group. There were no differences between the LPTI and the controls in terms of the variable sex of infant (44.3 vs. $44.4 \%$ ). Mean weight of the LPTI was $2310.7 \pm 361.9 \mathrm{~g}$, versus3147.4 \pm 608 . $\mathrm{g}$ for controls. Mean GA was35.7 \pm 0.8 weeks for cases and $39.1 \pm 1.0$ weeks for controls.

Table 2 shows admission/ readmission and mortality rate in late preterm and term infants.

More than half of the LPTI needed to be admitted to the NICU and LPTI had a mean hospital stay of $6.9 \pm 2.4$ days, vs. $4.25 \pm 1.9$ days for the control group ( $\mathrm{p}<0.0001)$. Three of the four deaths observed during the study were in the LPTI group. In two cases sepsis was the cause of death. Table 3 shows a comparison of the two groups in terms of neonatal variables.

Mean 5-minute Apgar scores also differed between the groups: 7.7 for LPTI vs. 9.0 for FTI $(\mathrm{p}<0.033)$.

The LPTI had higher rates of resuscitation in the delivery room, more frequent episodes of hypoglycemia ( $8.6 \%$ vs. $1.7 \%$ ).and greater hypothermia, with statistically significant differences in relation to the control group. A higher proportion of the LPTI needed phototherapy to treat neonatal jaundice (34.3\% vs. $7.8 \%$ ) and LPTI were more likely to need formula to supplement their diets. With regard to neonatal respiratory diseases, it was observed that it was more in LPT (32.9\% vs. $13.9 \%)$ and incidence rates of HMD, TTNB, pneumonia and apnea of prematurity were all higher among the cases. Table 3 lists the results for the most important neonatal variables studied, stratified by GA. We observed that frequency and relative risk (compared with the control group) of intercurrent neonatal conditions reduced with each extra week of GA. Even so, LPTI born at 36 weeks gestational age were still significantly different from the FTI in terms of a large number of variables

Table 1 Maternal obstetrical factors of studied groups.

\begin{tabular}{|c|c|c|c|}
\hline & LPT $(\mathrm{n}=70)$ & Term $(\mathrm{n}=180)$ & $\mathrm{p}$ value* \\
\hline \multicolumn{4}{|l|}{ Indication for delivery } \\
\hline Onset of labor (n, \%) & $20(28.6 \% 0$ & $97(53.9)$ & \multirow{4}{*}{$<0.0001 *$} \\
\hline $\begin{array}{l}\text { Rupture of amniotic } \\
\text { membrane }(\mathrm{n}, \%)\end{array}$ & $19(27.1)$ & $35(19.4)$ & \\
\hline Ante partum hemorrhage/ & $8.0(11.4)$ & $2.0(1.1)$ & \\
\hline Fetal distress $(\mathrm{n}, \%)$ & $15(21.4)$ & $25(13.9)$ & \\
\hline \multicolumn{4}{|l|}{ Mode of delivery } \\
\hline Cesarean section $(\mathrm{n}, \%)$ & $45(64.3)$ & $71(39.4)$ & \multirow[b]{2}{*}{$<0.0001 *$} \\
\hline Vaginal delivery $(\mathrm{n}, \%)$ & $25(35.7)$ & $109(60.6)$ & \\
\hline \multicolumn{4}{|l|}{ Indication for C-section } \\
\hline Breech presentation $(\mathrm{n}, \%)$ & $25(35.7)$ & $15(8.3)$ & \\
\hline $\begin{array}{l}\text { Previous cesarean section } \\
(\mathrm{n}, \%)\end{array}$ & $15(21.4)$ & $25(13.9)$ & \\
\hline Placenta previa $(\mathrm{n}, \%)$ & $5(7.1)$ & $16(8.9)$ & \\
\hline
\end{tabular}




\begin{tabular}{|l|l|l|l|}
\hline Elective C-section (n, \%) & $0(0.0)$ & $15(8.3)$ & \multicolumn{1}{|l|}{$<\mathbf{0 . 0 0 0 1} *$} \\
\hline \multicolumn{2}{|l|}{ Other complications of pregnancy } & $18(10)$ & 0.736 \\
\hline Diabetes (n, \%)y & $6(8.60$ & $26(14.4)$ & $\mathbf{0 . 0 1 2}$ \\
\hline HDP (n, \%)z & $19(27.1)$ & $1(0.6)$ & 0.309 \\
\hline Cardiac of newborn (n,\%) & $1(1.4)$ & &
\end{tabular}

*Total late preterm infants compared with term infants.

HDP = hypertensive disorder of pregnancy; NICU = neonatal intensive care unit. y Including gestational and established .z Hypertensive disorder of pregnancy including chronic hypertension, pregnancy-induced hypertension, and preeclampsia.

Table 2 Incidence of NICU admission/ readmission and mortality rate in late preterm and term infants.

\begin{tabular}{|l|l|l|l|l|l|l|}
\hline & $\begin{array}{l}34 \text { wks } \\
(\mathrm{n}=12)\end{array}$ & $\begin{array}{l}35 \text { wks } \\
(\mathrm{n}=28)\end{array}$ & $\begin{array}{l}36 \mathrm{wk} \\
(\mathrm{n}=30)\end{array}$ & $\begin{array}{l}\text { LPT } \\
(\mathrm{n}=70)\end{array}$ & $\begin{array}{l}\text { FT } \\
(\mathrm{n}=180)\end{array}$ & value* \\
\hline $\begin{array}{l}\text { Admission } \\
(\mathrm{n}, \%)\end{array}$ & $10(83.3 \%)$ & $14(50.0 \%)$ & $13(43.3 \%)$ & $37(52.9)$ & $48(26.7 \%)$ & $\mathbf{0 . 0 0 1 * *}$ \\
\hline $\begin{array}{l}\text { Readmission } \\
(\mathrm{n}, \%)\end{array}$ & $1(8.3 \%)$ & $1(3.6 \%)$ & $1(3.3 \%)$ & $3(4.3)$ & $4(2.2 \%)$ & 0.479 \\
\hline $\begin{array}{l}\text { Mortality } \\
(\mathrm{n}, \%)\end{array}$ & $2(16.7 \%)$ & $1(3.6 \%)$ & $0(0.0 \%)$ & $3(4.3)$ & $1(0.6 \%)$ & $\mathbf{. 0 0 1 * *}$ \\
\hline
\end{tabular}

*Total late preterm infants compared with term infants.

\section{DISCUSSION}

In the studied neonates, there were no statistically significant differences of gender distribution among both groups. This was different from that reported by Challis et al., (2013) who suggested that the incidence of preterm birth is also higher in pregnancies carrying a male fetus; the male: female difference is greater in earlier preterm pregnancy and explained this by the fact that placental or chorionic trophoblastic cells from pregnancies with a male fetus produced more proinflammatory $\mathrm{TNF} \alpha$ and granulocyte colony stimulating factor (G-CSF) than cells from pregnancies with a female fetus, more prostaglandin synthase (PTGS-2) and less prostaglandin dehydrogenase (PGDH).[10]. In this study extremes of reproductive age groups are at a higher risk of preterm labor. Findings from retrospective cross-sectional study of Carter et al., (2011) using routine delivery data from all births in San Antonio/Bexar County, Texas between 2000 and 2008 and including 259,576 births, corroborated that age $\leq 17$ and $\geq 35$ is associated with increased risk of late preterm birth.[11]

In our study we did not find any significant association of late preterm birth with parity, it was unlike what observed by Melamed et al, 2011.[12] Till today, there is a controversy regarding association between induced and spontaneous abortions and risk of late preterm birth. In a review article published in 2012 out of 24 considered papers, [12] reported an increased risk of preterm birth among women reporting previous abortions).[13]. In the present study, we found an increased incidence of

late preterm birth with certain maternal diseases as hypertension Carter et al, (2011) co morbidities, in particular hypertension and gestational diabetes have been associated with the risk of LPB.[11]

Mode of delivery also had a significant association regarding term deliveries and cases of late preterm births. Late preterm infants were more likely to be delivered by 
cesarean section than term infants. These results were comparable to others.[14]

Evaluating the newborns birth weight in our study showed that there was a significant progressive increase in the mean birth weight with increasing the GA this finding was similar to what reported by Santos(Santos et al., 2017).[15]

Mean birth weight s significantly higher in FT. Betul et al., (2018) also concluded that all measurements of late preterm infants were smaller than those of term infants.[16]

In our study, the LP infants had a higher incidence of formula feeding compared with full term infants, bottle feeding was significantly higher in LP infants group which is similar to the results of other studies.[17]Some of the reasons postulated for this have been decreased alertness; poor latching-on skills, decreased oro-motor tone, disorganized sucking patterns and poor suck swallow coordination. The immature suction pressures produced have been shown to reduce lactogenesis. Thus, there may be difficulty in establishing maternal-infant bonding and successful breastfeeding. Furthermore, feeding issues can lead to decreased caloric intake and dehydration which can further exacerbate other complications like hypoglycemia, hyperbilirubinemia, respiratory distress and temperature instability.[18]

Table 3 Neonatal complications of late preterm and term infants.

\begin{tabular}{|c|c|c|c|c|c|c|}
\hline & $\begin{array}{l}34 \text { wks } \\
(\mathrm{n}=12)\end{array}$ & $\begin{array}{c}35 \text { wks } \\
(\mathrm{n}=28)\end{array}$ & $\begin{array}{l}36 \mathrm{wks} \\
(\mathrm{n}=30)\end{array}$ & $\begin{array}{c}\text { LPT } \\
(n=70)\end{array}$ & $\begin{array}{c}\text { Term } \\
(\mathrm{n}=180)\end{array}$ & p value* \\
\hline $\begin{array}{l}\text { APGAR at } 5 \text { minute } \\
(\text { Mean } \pm \text { SD) }\end{array}$ & $7.2 \pm 1.6$ & $7.7 \pm 1.8$ & $8.1 \pm 1.2$ & $7.7 \pm 1.5$ & $9.1 \pm 1.1$ & $<0.001 * *$ \\
\hline $\begin{array}{l}\text { NICU hospital stay } \\
\text { (mean } \\
\pm \text { SD), d }\end{array}$ & $7.1 \pm 1.9$ & $8.4 \pm 2.6$ & $5.2 \pm 1.2$ & $6.9 \pm 2.4$ & $4.25 \pm 1.9$ & $<0.001 * *$ \\
\hline Resp. Diseases & $9(75.0)$ & $12(42.9)$ & $2(6.7)$ & $23(32.9)$ & $25(13.9)$ & $<0.001 * *$ \\
\hline Early onset $(\mathrm{n}, \%)$ & $1(8.3)$ & $1(3.6)$ & $0(0.0)$ & $2(2.9)$ & $1(0.6)$ & $0.013 * *$ \\
\hline Late onset (n, \%) & $2(16.7)$ & $2(7.1)$ & $2(6.7)$ & $6(8.6)$ & $8(4.4)$ & 0.062 \\
\hline Convulsions (n, \%) & $1(8,3)$ & $2(7.1)$ & $0(0.0)$ & $3(4.3)$ & $1(0.6)$ & $0.013 * *$ \\
\hline $\begin{array}{l}\text { Bleeding tendency (n, } \\
\%)\end{array}$ & $0(0.0)$ & $2(7.1)$ & $0(0.0)$ & $2(2.9)$ & $1(0.6)$ & 0.062 \\
\hline $\begin{array}{l}\text { Hyperbilirubinemia } \\
\text { phototherapy }(\mathrm{n}, \%)\end{array}$ & $6(50)$ & $10(35.7)$ & $8(26.7)$ & $24(34.3)$ & $14(7.8)$ & $<0.001 * *$ \\
\hline Hypoglycemia (n, \%) & $2(16.7)$ & $3(10.7)$ & $1(3.3)$ & $6(8.6)$ & $3(1.7)$ & $<0.001 * *$ \\
\hline Hypothermia (n, \%) & $2(16.7)$ & $1(3.6)$ & $0(0.0)$ & $3(4.3)$ & $0(0.0)$ & 0.241 \\
\hline Hypocalcemia( n, \%) & $1(8.3)$ & $2(7.1)$ & $2(6.7)$ & $5(7.1)$ & $5(2.8)$ & 0.241 \\
\hline
\end{tabular}


"Total late preterm infants compared with term infants. TTN = transient tachypnea of newborn NICU = neonatal intensive care unit; PPHN = persistent pulmonary hypertension RDS = respiratory distress syndrome; $\mathrm{SD}=$ standard deviation NICU = neonatal intensive care unit PPHN = persistent pulmonary hypertension $\mathrm{RDS}=$ respiratory distress syndrome; $\mathrm{SD}=$ standard deviation

In our study, we also found that the rate of NICU admission increased the lower the gestational age. Similar results were reported by Ming-Luen.[19] In our study we reported that; neonatal mortality tend to increase for every week of decrease in gestational age. Different results were reported by Steure and coauthors.[20]

Late preterm infants in our study were found to have more neonatal complications compared to full-term infants. Nearly $32.9 \%$ of LPT infants had clinical symptoms of respiratory distress, and the most common cause of it in LPs was RDS. In this study the most common cause of NICU admission for LPI neonate was neonatal jaundice compared to of FT ones. Similarly Darcy (2009) and Premji et al., (2012) found that hyperbilirubinemia is the most common reason for admission in the LPI population as the peak serum bilirubin is often not seen until 5 to 7 days of life.[21,22]

In our study hypoglycemia was higher in LPT infants than full term ones with, and it decreased with increase of GA. Marrocchella et al., (2014) found that the

\section{REFERENCES}

[1] World Health Organization. Sexual and reproductive health. 2010. Available at:http://www.who.int/reproductivehealth/en/[D ate accessed: July 7, 2011].

[2] American Academy of Pediatrics. American College of Obste 7 tricians and Gynecologists. Guidelines for perinatal care. 5th ed. Elk Grove Village, IL: American Academy of Pediatrics; 2005.

[3] Kramer MS, Demissie K, Yang HM, et al. The contribution of mild and moderate preterm birth to infant mortality. JAMA 2000;284:8439. incidence of hypoglycemia and jaundice results significantly higher in all LPs, compared to FT infants and also found that hypoglycemia decreased with increase in GA.23This findings is explained by the fact that limited glycogen stores and rapid depletion of glucose stores from the metabolic demands of the newborn transition period can result in hypoglycemia, cold stress, poor suck/swallow ability and respiratory complications contribute to the risk of developing hypoglycemia.[21, 24]

In this study convulsion was significantly high in LPT infants compared to FT one, observed more in 34th and 35th WKs GA. In another study done by Hannan C et al., (2017) on neonates from 34th WKs GA to 39th WKs GA revealed that seizure incidence decreased by increase in GA.[25]

Our results showed that there was a higher need for ventilation in LP infants compared with full term infants In a similar study, Hibbard and his colleagues found that LP infants especially those delivered at 34 weeks required more oxygen supplementation.[26]

[4] Moutquin J- M. Classification and heterogeneity of preterm birth. BJOG 2003;110:30-3.

[5] Raju TN, Higgins RD, Stark AR, et al. Optimizing care and outcome for late-preterm (near-term) infants: a summary of the workshop sponsored by the National Institute of Child Health and Human Development. Pediatrics 2006;118:1207-14.

[6] Davidoff MJ, Dias T, Damus K, etal. Changes in the gestational age distribution among U.S. singleton births: impact on rates of late preterm birth, 1992 to 2002.

SeminPerinatol 2006;30:8-15. 
[7] Picone S, Paolillo P. Neonatal outcomes in a population of late-preterm infants. J Matern

Fetal Neonatal Med 2010; 23(S3):116-20.

[8] Escobar GJ,GreeneJD, Hulac P, etal. Rehospitalisation after birth hospitalisation: patterns among infants of all gestations. Arch Dis Child 2005;90:125-31.

[9] Subcommittee on Hyperbilirubinemia. Management of hyper-bilirubinemia in the newborn infant 35 or more weeks of gestation. Pediatrics 2010;114:297-316.

[10] Challis J1, Newnham J, Petraglia F, Yeganegi M, Bocking A. (2013): Fetal sex and preterm birth. Placenta2013; 34(2):95-9.

[11] Carter MF, Fowler S, Holden A, Xenakis E, Dudley D. The late preterm birth rate and its association with comorbidities in a populationbased study. Am J Perinatol. 2011; 28:703-7.

[12] Melamed N, Klinger G, TenenbaumGavish K, Herscovici T, Linder N, et al. Shortterm neonatal outcome in low-risk, spontaneous, singleton, late preterm deliveries. Obstet Gynecol. 2011; 114:253-60.

[13] Thorp JM, Hartmann KE, Shadigian E. Long-term physical and psychological health consequences of induced abortion: Review of the evidence. ObstetGynecolSurv;2013: 58:6779.

[14] Laughon SK, Reddy UM, Sun L, Zhang J. Precursors for late preterm birth in singleton gestations. ObstetGynecol. 2010; 116:10471055 .

[15] Santos, Viviane Martins, Formiga, CibelleKayenne Martins Roberto, de Mello, Paulo: Late preterm infants' motor development until term age. Clinics, 2017:72(1), 17-22.

[16] BetulSIYAHBILGIN, Ozgun UYGUR, Demet TEREK1@, Ozge ALTUN

KOROGLU,Mehmet YALAZ, Mete AKISU, Ozgur ${ }^{\wedge}$ OGULU, Nilgun KULTURSAY,

Reference values of anthropometricmeasurements in healthy late preterm and term infants. 2018; 48: 862-872.
[17] Walker M. Breastfeeding the late preterm infant. Journal of Obstetric, Gynecologic \& Neonatal Nursing, 2011; 37:692-701.

[18] Ludwig SM. Oral feeding and the late preterm infant. Newborn and Infant Nursing Reviews 2013; 7:72-5.

[19] Ming-Luen Tsai, Reyin Lien, Ming-Chou Chiang, Jen-Fu Hsu, Ren-HueiFu, Shih-Ming Chu, Chang-Yo Yang, Peng-Hong Yang, "Prevalence and Morbidity of Late Preterm Infants: Current Status in a Medical Center of Northern Taiwan", Pediatrics \&

Neonatology,(2012): Volume 53, Issue 3, Pages 171-177, ISSN 1875-9572.

[20] Steurer, M.A. , Baer, R.J. , Keller, R.L.Gestational age and outcomes in criticalcongenital heart disease(2017) Pediatrics, 199:288.

[21] Darcy, A. Complications of the late preterm infant. Journal of Perinatal Neonatal Nursing. 2009; 23(1), 78-86.

[22] Premji, S., Young, M., Rogers, C., \&Reily, $\mathrm{S}$. Transitions in the early-life of late preterm infants. Journal of Perinatal \& Neonatal Nursing.2012; 26(1), 57-68.

[23] Marrocchella S1, Sestilli V1, Indraccolo U2, de Rosario F1, Castellana L3, Mastricci AL1, Calo' A4, Magaldi R4, Del Bianco A1, Greco P1, Matteo M1. Late preterm births: a retrospective analysis of the morbidity risk stratified for gestational age. Springerplus. 2014; 3:114.

[24] Gyamfi-Bannerman, C, Thom, EA, Blackwell, SC. "Antenatal betamethasone for women at risk for late preterm delivery". N Engl J Med. vol. 374. 2016 Apr 7. pp. 1311-20.

[25] Hannah C, Renee A, Tammay N, Courtney $\mathrm{J}$, et al. Seizures in pre term neonates: A Multicenter Observational Cohort Study. PediatrNeurol 2017; 72:19-24.

[26] Hibbard, J. U., Wilkins, I., Sun, L., Gregory, K., Haberman, S., Hoffman, M., Zhang, J. Respiratory Morbidity in Late Preterm Births. JAMA : The Journal of the American Medical Association, 2010; 304(4), 419-425. 